\title{
Effects of a shading screen on microclimate and crop water requirements
}

\author{
Markus Möller • Shmuel Assouline
}

Published online: 13 September 2006

(C) Springer-Verlag 2006

\section{Erratum to: Irrig Sci}

\section{DOI 10.1007/s00271-006-0045-9}

In the section "Materials and methods", line 9, an error occurred. The correct sentence should read: Trans- planting was on 18 June 2004 in plots measuring $12 \times 4.8 \mathrm{~m}$ at a plant density of $3.12 \mathrm{~m}^{-2}$ and final harvest was on 15 November.

The online version of the original article can be found at http://dx.doi.org/10.1007/s00271-006-0045-9. 